\title{
Analysis of Micro Factors Affecting the Quality of Project Course in Higher Vocational Education
}

\author{
Xiaojing Ren \\ Liaoning Petro-chemical College \\ (China Liaoning121001)
}

\section{Keywords: Higher vocational classroom; Teaching quality; Micro factors}

\begin{abstract}
. with the advance of the curriculum reform in higher vocational education, the quality of classroom teaching has also changed. In the new curriculum reform, it put forward an innovative management system, and encourages the development of the curriculum by means of micro factors. Therefore, the development and utilization of micro factors according to local conditions has become one of the important measures of the new curriculum reform. To sum up, the purpose of this study is to tap the micro factors, and make the micro factors serve the quality of classroom teaching in higher vocational education, and to supplement and improve the current situation of the single teaching content.

The thesis is one of the research findings of "Empirical Study of Project-based Teaching to Improve the Quality of Classroom Teaching in Higher Vocational College" (Project number: 16YB019) which is a general project of "13th Five-Year" Higher Education Scientific Research Projects of the 2016 Chinese Higher Education Association

With the innovation system of China's higher vocational education, teaching quality has attracted more and more attention, and the quality of teaching affects the quality of vocational students and allocation of teaching resources. Under the guidance of the theory, higher vocational classroom meets the needs through interactive teaching. From the micro factors of teaching, this study puts forward policy suggestions on how to improve the classroom teaching quality of higher vocational education.
\end{abstract}

\section{Part One Micro factors affecting teaching}

Factor of teacher. Teachers occupy the leading position in higher vocational education, which is directly related to the quality of teaching. The factors of teacher include knowledge, skills, morality and so on. Higher vocational teachers should have professional knowledge and they can broaden students' horizons, and make the knowledge at the core of specialized knowledge can help higher vocational students shape knowledge structure. In addition, teachers are also the carriers of interpersonal communication and knowledge, and whether they can communicate effectively with students is related to the level of organization and management of teaching ability. In the design of higher vocational curriculum, teachers should absorb the advanced mode, and pay attention to the innovation of teaching methods with the application of heuristic teaching to the teaching of higher vocational education based on the relevant knowledge and practice showing the network multimedia technology to college students to arouse the enthusiasm of study and train the innovative thinking of higher vocational students and improve the level of continuing education of students. Higher vocational teachers' moral qualities is embodied by emotion, morality, adhering to strict in demands tireless in teaching others can enhance the teaching ability of teachers of higher vocational students caused by resonance.

Factor of students. The student is the main factor affecting the teaching order of students, good class atmosphere can promote higher vocational students' learning attitude to improve, promote the improvement of the initiative, and help students to cultivate creative ability, flexible use of knowledge and practice learning with classroom teaching to achieve the predetermined target needs for higher vocational college students self teaching quality management. The class system has hindered the students free elective, and students can not realize self management class, and the goal of diversification is difficult to realize which leads the quality of teaching to be just passable. 
Factor of management. The functions of the system structure of the management system and the system of teaching quality of higher vocational education, school management and department level play decisive role in classroom teaching, the school has a direct impact on class management, and with the implementation of line management through professional educational management, it can play a role in college. Most of higher vocational teaching management belong to formalism which ignores the actual content, and schools must improve flexibility, and play the overall co-ordination function of management.

\section{Part Two Problems of classroom teaching in higher vocational education}

Through the investigation and analysis, it is easy to see that due to the influence of many factors, the classroom teaching in higher vocational education is relatively backward. In general, there are still some problems in the classroom teaching of higher vocational education.

Lack of attention. In the development of quality education today, it promotes all-round development of higher vocational classroom teaching in the entrance examination, but seldom pay attention to the comprehensive development, most of the teaching departments, schools and parents is also biased to understand the microcosmic factor, which is leading to the neglect of teaching quality of higher vocational education.

Existing conditions fall behind. Most of the classroom teaching presents a unified model, and students shows a tired state for this teaching model with no enthusiasm. Not only the student, many teachers can clearly realize the influence of the teaching mode on the teaching effect, and the traditional teaching model can not meet the needs of the changing society and students. The teacher's scientific research ability is relatively weak, and there is not enough knowledge about the development and utilization of teaching resources, and it is not able to tap the teaching resources outside the textbooks. To a great extent, the lack of the use of resources has hindered the development of higher vocational teaching curriculum.

\section{Part Three Suggestions on improving teaching quality}

To solve the above problems, teachers must first recognize the single traditional teaching mode has been unable to adapt to current teaching needs, and teaching workers should betake to change ideas, and improve curriculum consciousness, strengthen training to improve the ability of teaching and research. To sum up, it is necessary to develop resources.

Clear teaching objectives. According to Piaget's theory of cognitive development, "in the course of students' physical and mental development, different age stages have different characteristics" [1]. Therefore, in the course arrangement, different teaching objectives should be formulated according to the characteristics of students in different ages. To targeted teaching content selection, students in every stage of its body have different characteristics on intelligence and learning ability, with the increase of age, their learning ability and learning attitude are constantly changing, and according to the characteristics of students of different grades of physical and mental development that is difficult to choose different the curriculum resources, or use the same resources to different courses. Therefore, in the course of screening the content of teaching, students should make full use of all kinds of knowledge in the field of discipline, and pay close attention to the close connection with various disciplines and even the external society, so as to avoid the separation of human culture from human beings. Curriculum developers not only have profound knowledge, but also have a high degree of comprehensive ability and innovative spirit, so as to develop a comprehensive ability courses.

Selection of classroom content. The development of higher vocational education resources is to use of resources to the practice of classroom teaching, so there must be a purpose to choose feasible material resources as teaching contents in the development making it into classroom teaching in teaching resources. In the actual teaching, the development of local resources is also affected by the students' knowledge, skills, quality and interest, the equipment of the school, the professional skills of teachers and the support of parents. Therefore, teachers should consider and prepare in advance 
when they are teaching. Teachers should also choose a variety of teaching methods in the classroom teaching and extracurricular practice. In the daily study, teachers should fully mobilize the initiative of the students, and let the students take the initiative to think and discuss in groups, so that there will be sparks of collisions between thought and thought. In the course of extracurricular practice, students are organized to visit, field trips and carry out special lectures. The combination of teaching practice in theory with the specific extracurricular can help students enhance the understanding of all resources, cultivate students' and thus greatly the widespread interest in learning to stimulate students' learning enthusiasm.

Carrying out practice vigorously. The compulsory education curriculum standard explicitly requests to train the student's independence and the autonomy, and raises the practical ability which the higher vocational student should have with the imagination creation ability [2]. Therefore, in the development of higher vocational class, teachers should adjust measures to local conditions, pay close attention to practice at all times and strengthen the cultivation of students' practical ability. And in the actual classroom of higher vocational resources in the development and utilization of resources, the choice should be conducive to the practice of teaching activities to students active inquiry, planning making the personally experience as the main content, and teachers and students should do for everyone involved, everyone practice. Take advantage of all available opportunities to lead students boldly out of the classroom, out of the campus, and into the nature, into society, in the embrace of nature and society to absorb nutrition and thrive.

Language is an important tool for communication between teachers and students in teaching, and teachers need to do from easy to difficult, step by step to enable students to fully understand the content of teaching according to the understanding of the knowledge of students, from the cognitive perspective from the shallower to deeper, let the students have a more profound understanding of the teaching mode, so as to lay the foundation for development and utilization. Strong ability is an important feature of the course, teachers in the classroom teaching in addition to theoretical knowledge, more through classroom demonstration deepen students' visual impression, so as to guide the students to think for themselves on-site production and creation. As a result, many teachers will demonstrate their skills and techniques by demonstrating. In the design application, modeling and design of these courses, students can more clearly grasp the skills of classroom teaching.

Promoting group cooperation. Group cooperative learning not only allows students to learn to analyze problems independently, but also to increase awareness of teamwork. Therefore, teachers regard cooperative learning as an important way of learning and utilizing local resources. In higher vocational teaching courses, students can be grouped and explored, and then different division of work within the group, so that students can work together to accomplish teaching tasks. After each group completes the work, teachers carry shows on the appraisal in the class, selects "the most creative group" in the class and give the praise and the encouragement to the group. Primary school students in the continuous attempt can gradually enhance the ability to team work, enjoy the results of team work, but also can increase the sense of collective pride. Now, it is in the era of information, when vigorously develop and carry out higher vocational education development, in order to maximize stimulate the fun of learning, teachers can let students carry out independent inquiry. Teachers can delegate their power to students and use the current developed network technology and information technology to collect relevant information for teaching, so that they can make suggestions for improving their teaching level. In front of the teaching, students can be divided into several groups, and each group is assigned with a task to let the students to organize and arrange themselves, and they are encouraged to refer to the relevant books and the Internet and other information to complement and extend the knowledge of the textbook. And after the completion of the teaching, students can also be encouraged to use the network to study, so that they can expand their knowledge on the basis of learning. Inform the teaching content, let students use their spare time by reading books, Internet search and other features, understand teaching building cultural connotation, and the teaching contents in class discussion and questioning, completion of the course, 
by which students make their own efforts to obtain new knowledge to understand, master knowledge with learning that more skilled and solid.

Carry out teaching evaluation. Teaching evaluation is based on the curriculum objectives, and through certain methods, the teaching activities and results have the value of the judgment [3]. Tn the process of development the curriculum resources with local characteristics, teachers can carry out effective evaluation that can reflect the curriculum resources development effect, also can make the curriculum resource development problems in the process of getting feedback, but also as a direction for the development of curriculum resources. Evaluation is not only the evaluation of students' finished works, but also the evaluation of students' behavior in the whole process of learning. At the beginning of the class, an incentive based assessment model will greatly stimulate interest in learning. In the process of learning knowledge, in order to enable each student's potential to be excavated, individual counseling and the use of various resources play important roles in improving the quality of education process.

In short, vocational classroom resources diversification is a good supplement to the existing single teaching mode, and compared with the original model, flexible new teaching mode can greatly improve the students' enthusiasm and interest in classroom learning to help students to obtain more rich teaching knowledge. This article attempts to provide guidance for improving the quality of teaching in higher vocational education from the micro causes of the impact of various practical factors on the quality of higher vocational education.

\section{References}

[1] Yan Wu, Zuliang Liu.The world's trend of high-end development of higher education and China's coping strategy[J]. Higher Education Research in China, 2011(1): 23-27.

[2] Ye Chen, Chen $\mathrm{Xu}$, Keming Yuan.On the construction of modern university system from the perspective of talent training[J]. Chinese University Teaching, 2010(12): 62-64.

[3] Jisheng Wang. Human culture: re-understanding of the original meaning of educational activities[J]. Higher Education Research in China, 2010(2): 34. 36. 